\title{
The embryonic phase and its implication in the hatchling size and condition of Atlantic bobtail squid Sepiola atlantica
}

\author{
Marcelo Rodrigues • Ángel Guerra • \\ Jesús S. Troncoso
}

Received: 14 April 2010/Revised: 10 July 2010/ Accepted: 13 July 2010/Published online: 31 July 2010

(C) Springer-Verlag and AWI 2010

\begin{abstract}
Early life stages of cephalopods are somewhat complex due to the life history strategy or species specificity of generalized ontogenetic patterns and processes. This work aimed to determine the time length of embryonic development at different temperatures, and if the egg size is a determinant of hatchling size in Sepiola atlantica d'Orbigny, 1839-1842. Successful hatching occurred in $98.5-100 \%$ of the eggs for each female. As seen in other coleoid cephalopods, temperature determines the amount of time for embryonic development in S. atlantica, and the obtained data were very similar to other coleoid cephalopods. Developmental times for temperatures at $13 \pm 0.4^{\circ} \mathrm{C}$, $18 \pm 0.3^{\circ} \mathrm{C}$ and $16.4 \pm 1.1^{\circ} \mathrm{C}$ were $61.8 \pm 3.8,22.6 \pm 1.7$ and $40.1 \pm 4.8$ days. The duration of embryonic development and hatchling mantle length was not strictly related. The egg volume was positively related to hatchling mantle length. Our results provide new records on the duration of embryogenesis and other information on reproductive patterns in this species. Some hatching and post-hatching behaviour are shown and discussed.
\end{abstract}

Keywords Cephalopoda $\cdot$ Sepiola atlantica . Reproduction · Development · Hatchling

Communicated by H.-D. Franke.

M. Rodrigues $(\bowtie) \cdot$ J. S. Troncoso

Departamento de Ecología y Biología Animal,

Universidad de Vigo, 36310 Vigo, Pontevedra, Spain

e-mail: marcelorodrigues@uvigo.es

Á. Guerra

ECOBIOMAR, Instituto de Investigaciones Marinas,

CSIC, Vigo, Spain

\section{Introduction}

Development and reproductive trait analysis provide examples for most adaptive relationships and responses to intrinsic and extrinsic forces of selection acting throughout the life cycle (Boletzky 1993, 2003a; Stearns 2000). In natural populations, offspring size and egg size are classical life history traits which identify effects on hatchling size and competitive performance (Boletzky 1997, 2003b; Marshall and Keough 2007). However, most data are from empirical studies provided from laboratory observations, since field studies are lacking due to the logistical difficulties of experimentally manipulating population densities in natural settings (Svensson and Sinervo 2000).

In marine invertebrates, a change in hatchling size can be obtained by the adoption of intracapsular feeding on stored nutritive material or by the production of larger eggs (Boletzky 1997). Larger hatchlings are supposed to reduce susceptibility to predation (Steer et al. 2003) and starvation due to enhanced swimming ability and predatory competence in comparison with smaller hatchlings. This trade-off has been identified in different animal taxa, such as lizards (Svensson and Sinervo 2000), many marine invertebrates (Marshall and Keough 2007 a review) and cephalopods (Laptikhovsky and Nigmatullin 1993; Rodrigues et al. 2010; Steer et al. 2003, 2004; see also Boletzky 2003b and Villanueva and Norman 2008 for reviews). Moreover, differences in egg size and hatchling size seem to reflect ecosystem fluctuations, mainly temperature and food availability, such as those found during different spawning groups in the squid Illex argentines (Laptikhovsky and Nigmatullin 1993).

In cephalopods, the duration of embryonic development is dependent not only on species but also on temperature, as documented for several species (Boletzky 2003a; 
Villanueva and Norman 2008). In contrast to many other marine invertebrates (references in Marshall and Keough 2007), there is very little information on how maternal conditions affect the hatchling condition in cephalopods (Boletzky 2003b; Rodrigues et al. 2010; Steer et al. 2004). Therefore, it is beneficial to investigate whether egg size is a determinant of hatchling size in S. atlantica and whether temperature has an effect on this trait.

During embryonic development, prevailing environmental conditions may affect the physiological state of the developing larva (Giménez and Torres 2002), particularly in cephalopod paralarvae where the inner yolk sac provides energy for metabolism in learning activities such as predation (Boletzky 1974, 1993). Several authors have suggested that the transition from yolk utilization to active predation represents a critical period in the early life history of cephalopods (Boletzky 2003a; Vidal et al. 2002; Villanueva and Norman 2008). In paralarvae of chokka squid, Loligo reynaudii, rates of inner yolk utilization may be influenced by environmental temperature (Martins et al. 2010)

As observed in other sepiolids, Sepiola atlantica d'Orbigny, 1839-1842, transfers spermatophores to the female, who stores them in the bursa copulatrix, a large pouch lying on the visceral mass that allows the spermatangia to become attached (Rodrigues et al. 2009). This species is an intermittent terminal spawner (see Rocha et al. 2001), and this spawning strategy comprises groupsynchronous ovary maturation, multiple egg laying and deposition of egg clutches in different locations. Furthermore, the egg size shows a positive correlation with maternal size, and the female does not take parental care of its progeny (Rodrigues et al. 2010).

The goals of this study were to evaluate the influence of temperature on development in S. atlantica and to determine whether hatchling size is dependent on the duration of development, along with providing new information on post-hatching behaviour and condition.

\section{Materials and methods}

A total of twelve mated adult females were obtained during dedicated dives in the Ría of Vigo (NW Iberian Peninsula) $\left(42^{\circ} 14^{\prime} \mathrm{N} ; 8^{\circ} 47^{\prime} \mathrm{W}\right)$. The field collection and laboratory study were carried out between January and September 2009. Live specimens were immediately sent, with care, to the Marine Station of the University of Vigo in Toralla Island (ECIMAT-UVIGO). Collection depth was between 3 and $6 \mathrm{~m}$ in sandy substrate with no algae present.

Each individual was placed in a $20.21(30 \mathrm{~cm}$ long $\times 27 \mathrm{~cm}$ wide $\times 25 \mathrm{~cm}$ deep) glass tank with an open system of running seawater $\left(16.4 \pm 1.1^{\circ} \mathrm{C}\right)$. The bottom of the tanks was covered with $0.5-1 \mathrm{~cm}$ of fine sand from the type locality. The system received a natural photoperiod according to the season, roughly: spring 12:12 LD, summer 15:9 LD, autumn 12:12 LD, winter 9:15 LD.

Sepiolid squids were fed daily ad libitum with freshly collected adult mysid shrimps, Siriella armata and Leptomysis mediterranea. Females were always kept in isolation in the tanks and were never exposed to males in captivity, but all of them produced eggs that initiated development, thus indicating that spermatangia were present in the females.

Twelve spawns in aquaria were obtained (753 eggs) from the captive females. Eggs were laid during the night or early morning and were removed upon observation. Each clutch was divided into three groups exposed to different temperatures: $13 \pm 0.4^{\circ} \mathrm{C}(N=247), 18 \pm 0.3^{\circ} \mathrm{C}(N=251)$ and natural variation $(\mathrm{NV}=255) 16.4 \pm 1.1^{\circ} \mathrm{C}$. Eggs from each female were maintained in small nylex mesh bags $(0.5 \mathrm{~mm}$ mesh) where the spawning date, egg volume and "mother" were recorded. Bagged eggs were checked daily in routine controls at 8:00-9:00 a.m. and p.m., allowing us to record roughly from each clutch the emergence of the first hatchling, the diel hatching time and rate of successful hatchings for each female at the different temperatures.

After hatching, following Messenger (1985), a total of 721 specimens were anaesthetized using a $1 / 1 \mathrm{ASW}-\mathrm{MgCl}_{2}$ (7.14\%) solution for $1 \mathrm{~min}$ in order to reduce their mobility. Dorsal mantle length (ML) and total length $(\mathrm{TL}=$ from posterior tip of the mantle to tip of the longest arm) were measured to $0.01 \mathrm{~mm}$ accuracy and weighed (BW) to $0.001 \mathrm{~g}$ immediately after being anaesthetized. The same measurements were made on each female immediately after death. Once measured, hatchlings were maintained in the same conditions as the adults and juveniles of the mysid shrimps mentioned above were offered.

All measurements were made using a stereomicroscope (Nikon SMZ-1500). The image was calibrated on a video monitor, and measurements were taken directly from the screen utilizing an image analyser (Nikon, NIS-Elements).

Egg volume (EV) was approximated using the formula for the volume of a prolate ellipsoid, (4/3) $\pi L W^{2}$ (within $0.01 \mathrm{~mm}^{3}$ ) (see Rodrigues et al. 2010), where $L=\mathrm{egg}$ length $(\mathrm{mm})$ and $W=$ egg width $(\mathrm{mm})$. All statistical analyses were performed using SPSS software (SPSS statistics 17.0).

In addition, a number of hatchlings (Fig. 1) were fixed in Bouin's fixative and preserved in 70\% EtOH (25 replicas in total). These specimens were dehydrated in a graded series of ethanol, cleared with toluene and embedded in paraffin. Cross- and frontal sections of $7 \mu \mathrm{m}$ were mounted on slides and stained with haematoxylin and eosin. 


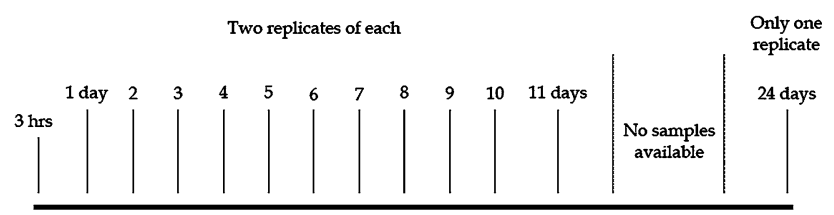

Sampling regime

Fig. 1 Scheme of the fixed post-hatching Sepiola atlantica $(N=25)$ to make histological sections used in this study

\section{Results}

Egg laying began between 67 and 104 days after females were collected. Of the twelve females, five deposited four egg clutches. The number of laid eggs per clutch was highly variable ranging between 2 and 86 eggs, with an apparent decrease in the number of eggs laid with time. The individual egg volume varied between 47.81 and $182.45 \mathrm{~mm}^{3}$ (53.29 $\pm 27.12 \mathrm{~mm}^{3}$; mean \pm standard deviation $)$.

The embryonic development in terms of time duration was strictly dependent on temperature (Fig. 2). The slowest rate in developmental time occurred with samples incubated at $13^{\circ} \mathrm{C} \quad(N=247), 61.8 \pm 3.8$ days. Eggs at $16.4 \pm 1.1^{\circ} \mathrm{C}(N=251)$ hatched after $40.1 \pm 4.8$ days. At $18^{\circ} \mathrm{C}(N=251)$, hatching occurred after $22.6 \pm 1.7$ days. Successful hatching was recorded in $98.5-100 \%$ of all the eggs laid.

Hatchling's ML varied from 1.1 to $1.7 \mathrm{~mm}(1.5 \pm$ $0.3 \mathrm{~mm})$, and TL ranged between 2.6 and $3.6 \mathrm{~mm}$ $(3.2 \pm 0.5 \mathrm{~mm})$. BW was 0.077 up to $0.098 \mathrm{~g}(0.081 \pm$ $0.02 \mathrm{~g})$. There was no relationship between hatchling length and weight $\left(r^{2}=0.36, n=721, P>0.05\right)$.

Hatchling ML was positively related to $\mathrm{EV}\left(r^{2}=0.69\right.$, $n=721, P<0.001$ ), which is represented by the following linear equation: $M L=0.904+0.007 E V$ (Fig. 3). However,

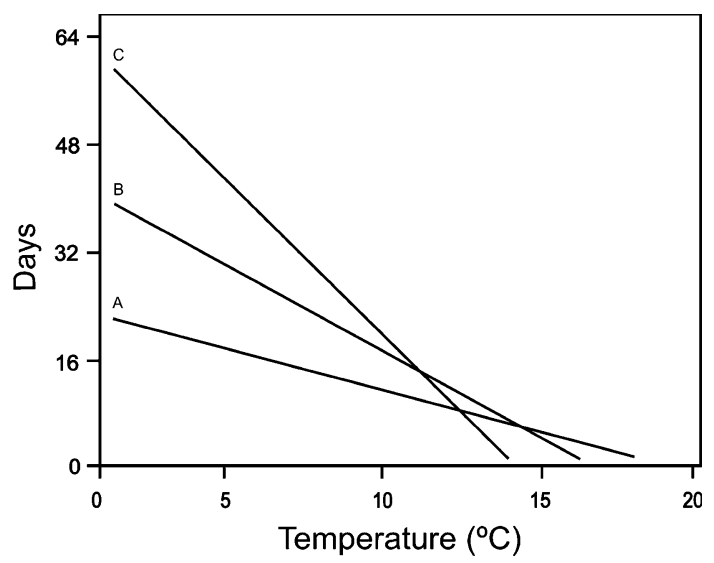

Fig. 2 S. atlantica. Schematic representation of embryonic developmental duration at different temperatures. Line $A$ represents the embryonic development at $18 \pm 0.3^{\circ} \mathrm{C}$; line $B$ at $16.4 \pm 1.1^{\circ} \mathrm{C}$; line $C$ at $13 \pm 0.4^{\circ} \mathrm{C}$ hatchling ML was not affected by neither temperature nor corresponding developmental time duration $(F=1.34$, $n=721, P>0.05)$.

Hatching and post-hatching behaviour

Of the 721 successful hatchings obtained, $96.3 \%$ took place during the night or early morning, and the rest during daylight or early evening. Hatching was achieved with vigorous mantle contractions. To leave the egg case, the hatchling possibly utilized the terminal spine as auxiliary equipment along with the hatching gland (see Boletzky 1991).

Newly hatched individuals showed expanded chromatophores of dark brown colour on a yellowish background along the whole body, and they often assumed a "flamboyant" arm display (as shown in Mauris 1989, Fig. 2- PB1). This posture consisted of the following arm patterns: (1) the dorsal and laterodorsal arms were stretched upwards perpendicularly to the body axis; (2) the lateroventral and ventral arms together were stretched downward on either side; and (3) the tips of all the arms were rolled in.

Hatchlings were generally less active during daylight hours, and juveniles remained at the bottom of the tank attempting to bury themselves in the sand. However, after a few hours (4-6 h), all the animals tried to bury in the substrate (sand grain size between 0.25 and $0.125 \mathrm{~mm}$ ), but with varying levels of success. These attempts consisted in contractions and expansions of the mantle while the animal was sitting on the substrate (first phase, cf. Boletzky and Boletzky 1970). Subsequent attempts consisted of the juveniles gathering sand particles (second phase) with outstretched laterodorsal arms, with varying success. A complete burying sequence (see Rodrigues et al. 2010) was observed after 4 days.

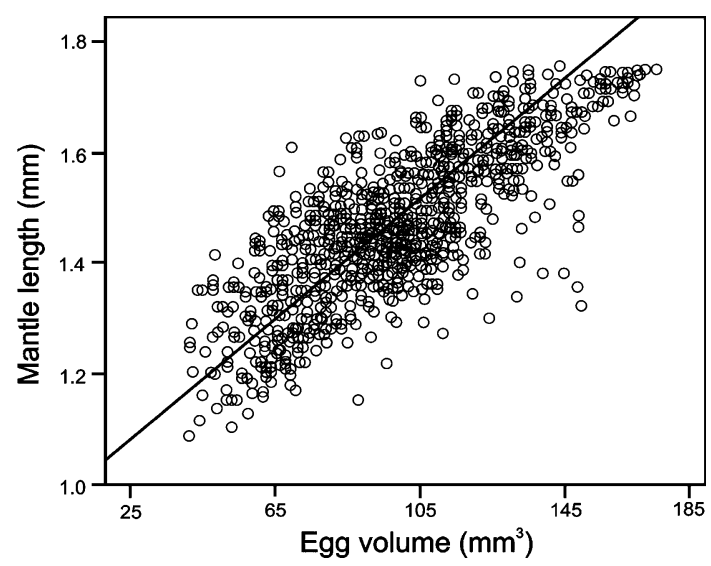

Fig. 3 S. atlantica. Relationship between egg volume $\left(\mathrm{mm}^{3}\right)$ and hatchling mantle dorsal length $(\mathrm{mm})$ fitted by a linearized calibration function, which explained $69 \%\left(R^{2}\right)$ of the associated variance 

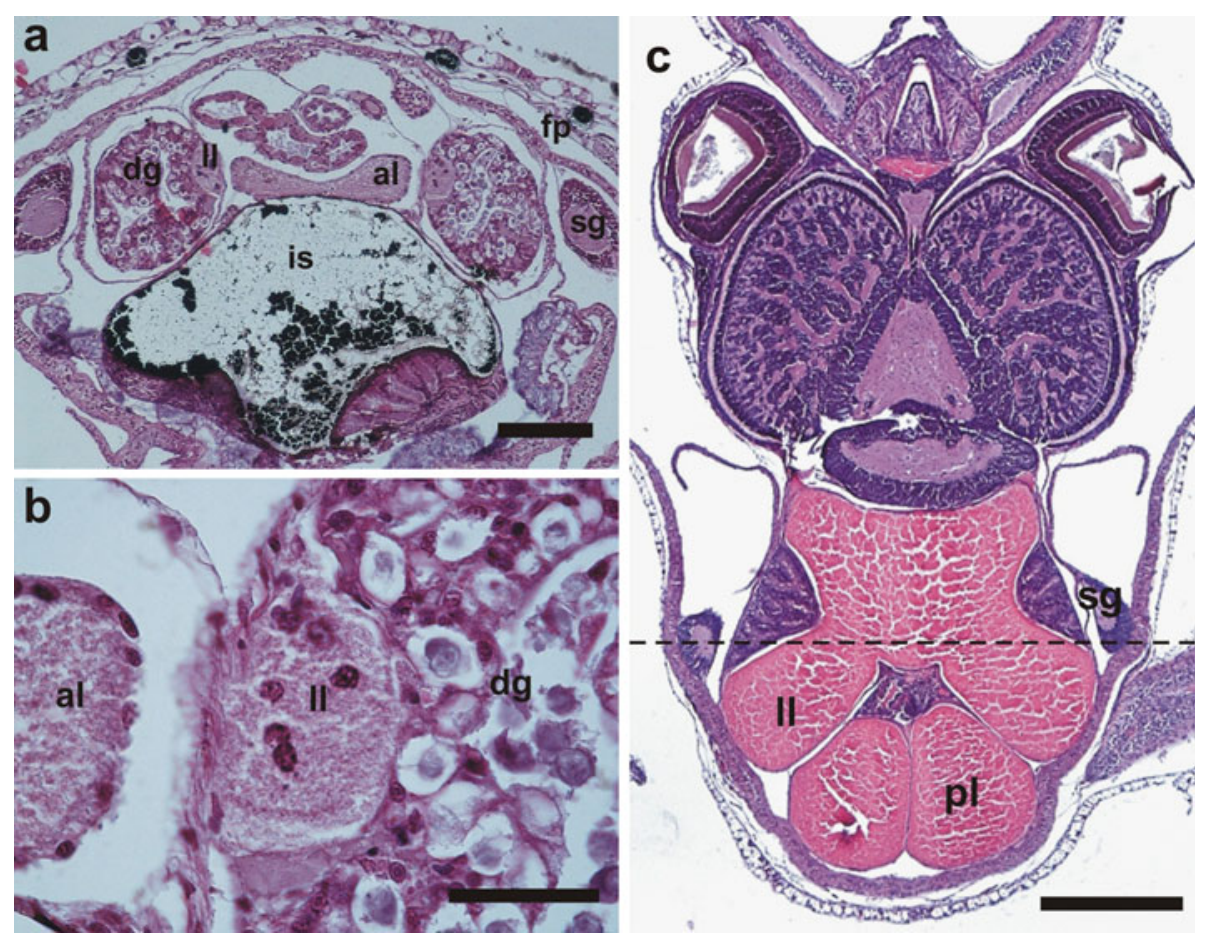

Fig. 4 Histological sections of Sepiola atlantica. a Cross-section of a hatchling at 24 days age on $10 \times$ magnification showing the rest of inner yolk sac; note the lateral lobe $(l l)$ as two round structures embedded in the digestive gland $(d g)$ and the transversal structure lying between them, on top of the ink sac (is), which is the middle part of the anterior lobe (al); b The same section at $60 \times$ magnification

Although hatchlings possess yolk reserves (inner yolk sac) (Fig. 4), they are poised to hunt mysid shrimp of the equal size $1 \mathrm{~h}$ post-hatching. This initial innate predatory response was not always successful but gradually improved. Hatchlings showed expanded dark brown chromatophores when directing attention to the prey. Afterwards, they moved quickly towards the prey in order to attain appropriate attacking distance (Messenger 1968). Prior to attack, hatchlings contracted all chromatophores and consequently turned virtually transparent. Arms were spread to form a circular crown, to enable the tentacles to be rapidly shot out (generally to the dorsal side in the middle of the mysid shrimp). If the attack was successful, the tentacles were quickly retracted with the prey. When the tentacles were retracted (with or without prey), the animals resumed a dark brown colour.

Although most hatchlings had eaten mysid shrimp within the first few days post-hatch, 97\% died between 3 and 6 days after hatching. One individual survived to 24 days old.

Histological analyses demonstrated that yolk was present in all hatchlings between 0 and 6 days old $(N=14)$. From 7 to 9 days old, only 2 of 6 replicas $(N=6)$ showed traces of yolk. The hatchlings 10 and 11 days old $(N=4)$ detailing the lateral lobe embedded admedially in the diverticula of the digestive gland, the middle part of anterior lobe is visible; c Frontal (horizontal) section of a hatchling $3 \mathrm{~h}$ old at $4 \times$ magnification. The dotted line indicates where the sections showed in figures (a) and (b) were made. Scale bars: $50 \mu \mathrm{m}(\mathbf{a}), 100 \mu \mathrm{m}(\mathbf{b})$, $0.5 \mathrm{~mm}$ (c) $\mathrm{sg}$ stellate ganglion; $f p$ fin pouch

had no traces of yolk. Nevertheless, the single juvenile that reached 24 days old showed traces of yolk (Fig. 4).

\section{Discussion}

Spawning behaviour observed in this study was similar to those shown in previous studies (Rodrigues et al. 2010). As in other coleoid cephalopods, S. atlantica showed an inverse relationship between temperature and developmental duration (Boletzky 2003a). The duration of development was similar to that observed by Boletzky (1983) in Sepiola robusta. However, the mean time was $50 \%$ lower than in the sepiolidae Euprymna tasmanica reared at the same temperature $\left(18^{\circ} \mathrm{C}\right.$, Steer et al. 2004). Hatching lasted for 23 days in S. atlantica at a mean temperature of $14.4^{\circ} \mathrm{C}$ in northern Welsh waters (Jones and Richardson 2010), which is comparable to our results at $18^{\circ} \mathrm{C}$.

Our comparison between the three tested temperatures did not show apparent differences in hatching success $(98.5-100 \%)$. Since high hatching rates were obtained at all temperatures examined (with no malformations), our results suggest that $S$. atlantica is adapted to living in waters ranging between 13.0 and $18.0^{\circ} \mathrm{C}$. On the other 
hand, Steer et al. (2004) observed in E. tasmanica that hatching success is positively correlated with offspring size.

We do not have direct evidence relating to how long the female can store sperm in the bursa copulatrix. This is mainly because we do not know when the females in our experiments mated in the wild. However, we have evidence that female $S$. atlantica can store viable sperm for at least 104 days, which was the maximum time fertilized eggs were spawned in our experiment.

This study revealed a positive effect of egg size on hatchling size in captive $S$. atlantica. This result is supported by the positive trade-off between maternal fitness, which determines egg size and trade-offs previously identified by Rodrigues et al. (2010) in the same laboratory conditions. Such features are normally found in direct marine developers which have no parental care (Marshall and Keough 2007). However, as observed in the brighteye darters, Etheostoma lynceum, egg quality and size vary in successive spawning events (Heins et al. 2004). Thus, the basis of the trade-off between female fitness and hatchling size could be influenced by other factors (such as temperature, food availability and salinity) in the field (Boletzky 1997; Heins et al. 2004; Laptikhovsky and Nigmatullin 1993; Marshall and Keough 2007; Steer et al. 2004; Svensson and Sinervo 2000).

S. atlantica hatchling ML was similar to that observed in other sepiolid hatchling species (Boletzky 1983; Jones and Richardson 2010; Nabhitabhata et al. 2005), which ranged between 1.1 and $2.5 \mathrm{~mm} \mathrm{ML}$, with the exception of Rossia macrossoma where hatching $\mathrm{ML}$ was around $5 \mathrm{~mm}$ (Boletzky and Boletzky 1973).

\section{Hatching and post-hatching behaviour}

Apparently in most cephalopod species, a decrease in natural light triggers hatching, but why this occurs in one particular is due at the physiological state that is attained by the animal (Boletzky 1974). Summers (1985) observed laboratory hatching in Rossia pacifica that showed the same diel hatching cycle as $S$. atlantica. This type of "hatching strategy" is a form of minimizing vulnerability to predators. We have now additional evidence which suggests that two new traits occur during the hatching strategy. This includes the presence of a dark brown pattern, and the flamboyant arm display. The flamboyant posture especially allows the hatchling to convey a confounding picture to a potential predator. This posture is perhaps not only related to prey capture (Mauris 1989). Both traits may improve camouflage and may constitute part of the primary defence strategy of the juvenile sepiolid squid (Hanlon and Messenger 1996).
This study provides additional observations for the behavioural fitness of $S$. atlantica hatchlings without previous experience in burying and hunting. Juvenile cephalopods have a remarkable repertoire of actions that correspond to some "innate responses" similar to adult behaviour (Boletzky 1974; Villanueva and Norman 2008). Although very vulnerable to predation, sepiolid hatchlings mainly behave in a defensive way by burying into the sand and by showing body patterns and displays adapted for concealment in the given environment (Boletzky and Boletzky 1973; Boletzky 1974). Although kept in a tank without sand for weeks, occasional observations demonstrated that sepiolid hatchlings of several Sepiola and Sepietta species (Boletzky 1983, 2003a; Boletzky and Boletzky 1973) bury when sand is present using similar techniques observed in our study.

This study demonstrates that $S$. atlantica possesses the innate predatory attack response $1 \mathrm{~h}$ post-hatching while still possessing yolk reserves. This result is in disagreement with that observed in the same species by Jones and Richardson (2010), who found that individuals began hunting at 6 days old. In contrast, other studies have shown that newly hatched cuttlefish (Sepia officinalis) began their predatory attacks at 24-48 h post-hatching (Wells 1958), with the precise sequence of motor actions observed in mature adults (Messenger 1968).

High mortality was still observed, despite traces of yolk in juvenile $S$. atlantica (Fig. 4). This suggests the existence of a critical period (cf. Vidal et al. 2002) in the early life history in $S$. atlantica. Based on juvenile mortality, Jones and Richardson (2010) suggested that the first 40 days are critical in the life cycle of the species, although in their study no inner yolk was observed after 20 days old. The phenomenon of critical period was also observed in some squid species reared in laboratory up to date (e.g., Loligo opalescens, Vidal et al. 2002). However, some extrinsic factors can be affecting in this aspect, like food availability, substrate type and light cycle (Hanlon et al. 1997; Vidal et al. 2002).

Post-hatch conditions were similar for all hatchlings, despite being raised at different developmental temperatures. This may have changed the physiological consumption of the yolk (Giménez and Torres 2002). Unfortunately, we had no individual temperature information and, consequently, we cannot prove this. Yolk consumption was studied in crabs (Chasmagnathus granulate), with salinity as the variable factor, and although salinity stress resulting in an increase in egg size (Giménez and Anger 2001), it was demonstrated that changes in salinity may have negative consequences in the growth rates at early juvenile stages (Giménez and Torres 2002). Future projects would need to address the variability in 
yolk consumption in $S$. atlantica hatchlings under various environmental conditions.

Although this is one of the first ecological trade-off investigations in the family Sepiolidae, our data and the previously reported correlation in maternal fitness and egg size (Rodrigues et al. 2010) support the idea that maternal fitness is a determinant of hatchling size in S. atlantica. Moreover, the current results indicate future areas of research in sepiolid squids, which may be fruitful towards understanding the innate behavioural response and the costs of metabolism during the transition from yolk utilization to active prey ingestion.

Acknowledgments The authors are greatly indebted to Prof. Sigurd von Boletzky (Observatoire Océanologique de Banyuls sur mer, Laboratoire Arago) for his attention, time, and fruitful advice, as well as the hosting facilities offered in his institute. We are also grateful to Manuel E. Garcí and Jose M. Antonio of ECOBIOMAR (IIM, CSIC) for their assistance in the sample collections and histology. Thanks to Katharine Ni Mhurchú and Fiona Read for their cordial help with the English. The first author was supported by a financial grant Estadias en Centros de Investigación from the "Universidade de Vigo" and a fellowship from the programme Axudas Predoutorais from the same institution.

\section{References}

Boletzky Sv (1974) The "larvae" of cephalopoda: a review. Thalass Jugosl 10:46-76

Boletzky Sv (1983) Sepiola robusta. In: Boyle PR (ed) Cephalopod life cycles. Species accounts, vol 1. Academic Press, London, pp 31-52

Boletzky Sv (1991) The terminal spine of sepiolid hatchlings: its development and functional morphology (Mollusca, Cephalopoda). Bull Mar Sci 49:107-112

Boletzky Sv (1993) Development and reproduction in the evolutionary biology of cephalopoda. Geobios M S 15:33-38

Boletzky Sv (1997) Developmental constraints and heterochrony: a new look at offspring size in cephalopod molluscs. Geobios M S 21:267-275

Boletzky Sv (2003a) Biology of early life stages in cephalopod molluscs. Advanc Mar Biol 44:144-203

Boletzky Sv (2003b) A lower limit to adult size in coleoid cephalopods: elements of a discussion. Berl Paläobiol Abh 3:19-28

Boletzky Sv, Boletzky MVv (1970) Das Eingraben in Sand bei Sepiola und Sepietta (Mollusca: Cephalopoda). Rev Suisse de Zool 77:536-548

Boletzky Sv, Boletzky MVv (1973) Observations on the embryonic and early post-embryonic development of Rossia macrossoma (Mollusca, Cephalopoda). Helgoländer wiss Meeresunters 25:135-161

Giménez L, Anger K (2001) Relationships among salinity, egg size, embryonic development and larval biomass in the estuarine crab Chasmagnathus granulate, Dana 1851. J Exp Mar Biol Ecol 260:241-257

Giménez L, Torres G (2002) Larval growth in the estuarine crab Chasmagnathus granulate: the importance of salinity experienced during embryonic development, and the initial biomass. Mar Biol 141:877-885
Hanlon RT, Messenger JB (1996) Cephalopod behaviour. Cambridge University Press, United Kingdom

Hanlon RT, Claes MF, Ashcraft SE, Dunlap PV (1997) Laboratory culture of the Sepiolid squid Euprymna scolopes: a model system for bacteria-animal symbiosis. Biol Bull 192:364-374

Heins DC, Baker JA, Guill JM (2004) Seasonal and interannual components of intrapopulation variation in clutch size and egg size of a darter. Ecol Freshw Fish 13:258-265

Jones NJE, Richardson CA (2010) Laboratory culture, growth, and the life cycle of the little cuttlefish Sepiola atlantica (Cephalopoda: Sepiolidae). J Shellfish Res 29:241-246

Laptikhovsky VV, Nigmatullin ChM (1993) Egg size, fecundity, and spawning in females of the genus Illex (Cephalopoda: Ommastrephidae). ICES J Mar Sci 50:393-403

Marshall DJ, Keough MJ (2007) The evolutionary ecology of offspring size in marine invertebrates. Advanc Mar Biol 53:1-60

Martins RS, Michael JR, Vidal EAG, Moloney CL (2010) Effects of temperature on yolk utilization by chokka squid (Loligo reynaudii d'Orbigny, 1839) paralarvae. J Exp Mar Biol Ecol 386:19-26

Mauris ME (1989) Colour patterns and body postures related to prey capture in Sepiola affinis (Mollusca: Cephalopoda). Mar Behav Physiol 14:189-200

Messenger JB (1968) The visual attack of the cuttlefish Sepia officinalis. Anim Behav 16:342-357

Messenger JB (1985) Magnesium chloride as an anaesthetic for cephalopods. Comp Biochem Physiol 82C:203-205

Nabhitabhata J, Nilaphat P, Promboon P, Jaroongpattananon C (2005) Life cycle of cultured bobtail squid, Euprymna hyllebergi Nateewathana, 1997. Phuket Mar Biol Cent Res Bull 66:351-365

Rocha F, Guerra A, González AF (2001) A review of reproductive strategies in cephalopods. Biol Rev 76:291-304

Rodrigues M, Garcí ME, Guerra A, Troncoso JS (2009) Mating behaviour of the Atlantic bobtail squid Sepiola atlantica (Cephalopoda: Sepiolidae). Vie et Milieu 39:271-275

Rodrigues M, Garcí ME, Troncoso JS, Guerra A (2010) Burying behaviour of the, Atlantic bobtail squid Sepiola atlantica (Cephalopoda: Sepiolidae). Ital J Zoo 77:247-251

Rodrigues M, Garcí ME, Troncoso JS, Guerra A (2010) Spawning strategy in Atlantic bobtail squid Sepiola atlantica (Cephalopoda: Sepiolidae). Helgol Mar Res. doi:10.1007/s10152-0100199-y (in press)

Stearns SC (2000) Life history evolution: successes, limitations, and prospects. Naturwissenschaften 87:476-486

Steer MA, Pecl GT, Moltschaniwskyj NA (2003) Are bigger calamary Sepioteuthis australis hatchlings more likely to survive? A study based on statolith dimensions. Mar Ecol Prog Ser 261:175-182

Steer MA, Moltschaniwskyj NA, Nichols DS, Miller M (2004) The role of temperature and maternal ration in embryo survival: using the dumpling squid Euprymna tasmanica as a model. J Exp Mar Biol Ecol 307:73-89

Summers WC (1985) Ecological implications of life stage timing determined from the cultivation of Rossia pacifica (Mollusca: Cephalopoda). Vie Milieu 35:249-254

Svensson E, Sinervo B (2000) Experimental excursions on adaptive landscapes: density-dependent selection on egg size. Evolution 54(4):1396-1403

Vidal EAG, DiMarco FP, Wormuth JH, Lee PG (2002) Influence of temperature and food availability on survival, growth and yolk utilization in hatchling squid. Bull Mar Sci 71:915-931

Villanueva R, Norman MD (2008) Biology of the planktonic stages of benthic octopuses. Oceanogr Mar Biol Annu Rev 46:105-202

Wells MJ (1958) Factors affecting reactions to Mysis by newly hatched Sepia. Behaviour 13:96-111 